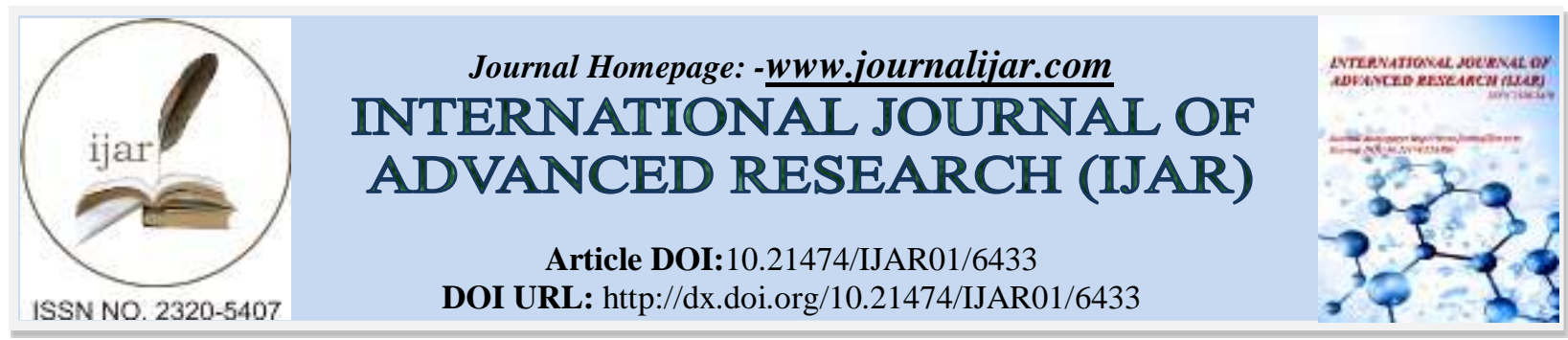

RESEARCH ARTICLE

\title{
MINIMALLY INVASIVE TECHNIQUE FOR TENOTOMY DURING MANAGEMENT OF CONGENITAL TALIPES EQUINOVARUS (CTEV) AFTER PONSETI CASTING BY USING LARGE BORE NEEDLE.
}

\author{
Ankur thakur ${ }^{1}$, Sumit Kumar ${ }^{1}$, Navneet Badoni ${ }^{2}$, Mohit Dhingra MS Orthopaedics ${ }^{3}$, Mohd Bilal kaleem ${ }^{1}$ and \\ Puneet Gupta MS orthopaedics ${ }^{4}$. \\ 1. Junior Resident, Department of Orthopaedics, Shri Mahant Indresh Hospital, Dehradun 248001. \\ 2. Professor, Department of Orthopaedics, Shri Mahant Indresh Hospital, Dehradun 248001. \\ 3. Associate Professor, Department of Orthopaedics, Shri Mahant Indresh Hospital, Dehradun 248001. \\ 4. Head of department,Department of Orthopaedics, Shri Mahant Indresh Hospital, Dehradun 248001.
}

\section{Manuscript Info}

(.........................

Manuscript History

Received: 03 December 2017

Final Accepted: 05 January 2018

Published: February 2018

\section{Keywords:-}

Congenital Talipes Equinovarus (CTEV), Ponseti Technique, Tenotomy, Tendo-Achilles, Thompson test .

\section{Abstract}

Introduction: Congenital talipes equinovarus (CTEV), also known as 'club-foot', is a common developmental disorder of the lower limb . CTEV, occurs 1 in 1000 live births. Tenotomy performed for tendo achilles for CTEV is routinely done percutaneously with a surgical blade. Through our study we are explaining technique for lengthening of tendo-achilles using large bore needle with safer and easier to use and with low complication rates.

Aim: To study the effectiveness of the technique.

Materials and Methods: A total of 30 children with 38 congenital CTEV were included our observational study. After performing serial ponseti casting, large bore needle used by minimal invasive percutaneous technique for doing tenotomy of tendo Achilles. Complication occurring during the procedure was noted. Thompson's test was performed after tenotomy.

Results: We found that this technique is very effective and safer to use than the commonly practiced percutaneous blade tenotomy .

Conclusion: Percutaneous minimal invasive tenotomy of tendo achilles with a wide gauge needle is easier, safer and technique with low complication. It causes less morbidity and carries lesser risk of complications when compared to a surgical blade.

Copy Right, IJAR, 2018,. All rights reserved.

\section{Introduction:-}

Congenital talipes equinovarus (CTEV), also known as 'club-foot', is a common developmental disorder of the lower limb. It is defined as fixation of the foot in adduction, in supination and in varus, i.e. inclined inwards, axially rotated outwards and pointing downwards . CTEV, occurs in one in 1000 live births ${ }^{1}$ and is one of the most common birth defects involving the musculoskeletal system. In $85 \%$ cases of CTEV tenotomy of tendo-achilles is performed following Ponseti casting ${ }^{2,3}$. It is most essential final step after ponseti casting for correction of equinus deformity and to achieve dorsiflexion ${ }^{2,3}$. 
Various techniques are used for tentomy such as mini-open and percutaneous tenotomy are performed. Percutaneous tenotomy for tendo-achilles lengthening by surgical knife is routinely performed but recently new technique by using large gauge surgical needle by minimally invasive technique is increasingly used over last few years which was first described by Minkowitz et al. ${ }^{4-6}$

Mostly tenotomy of tendo-achilles is done in OT by surgical blade, requiring general anaesthesia, which is cost effective and here in our study we are describing technique using large gauge needle which is cheaper, minimally invasive and out patient procedure , performed under local anaesthesia, involving minimal risks and complications( such as bleeding, neurovascular damage, pseudoaneurysm formation. Through our study we just want to increase awareness among new surgeons above recent advances in CTEV and easier method for tenotomy of tendo-achilles by using hypodermic large gauge needle.

\section{Materials and methods:-}

This study was performed in Department of orthopaedics, Shri Mahant Indresh Hopital, Dehradun from a period of november 2015 to December 2017.

\section{Inclusion criteria:-}

1. Patients with idiopathic CTEV

2. Patient treated with ponseti casting technique

3. Final Midfoot pirani score at zero after ponseti casting technique.

4. Primary and follow-up treatment done completely at our institution,

5. Age of the patient less than one year

\section{Exclusion criteria:-}

1. Patients with any syndromic stigmata .

2. Patient's parents not giving consent for study and not willing to be part of study.

After obtaining proper consent from the patients, for willingness to be the part of study . patient was than screened by pediatrician for any other congenital anomly or syndromic stigmata.

Final midfoot pirani score was calculated after final serial ponseti technique and which came out to be zero were included. Percutaneous tenotomy was done in orthopaedic outpatient basis, before procedure oral sedative was given for sedation purpose. An assistant is required for assisting and holding knee in 90 degree, patient was placed in supine position. Under aseptic precaution local anaesthesia( $1 \%$ lidocaine ,around $0.2 \mathrm{ml}$ was injected in subcutaneous tissue where tendo achilles is to be transected. Using the sharp edge of the needle( 16 gauge ), a sweeping motion of the beveled tip of needle is carried out to incise the longitudinal fibers of the tendo-achilles. Thompson's test was performed in every case to further confirm the completion of section. A complete tenotomy gives a negative Thompson's test due to absence of transmission of movements from calf to heel.

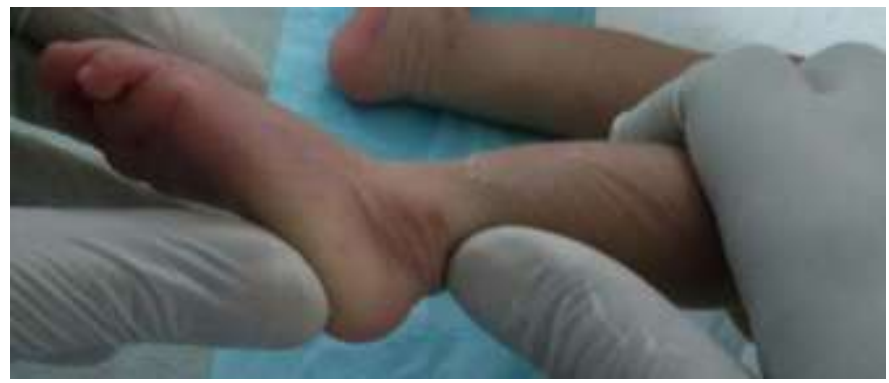




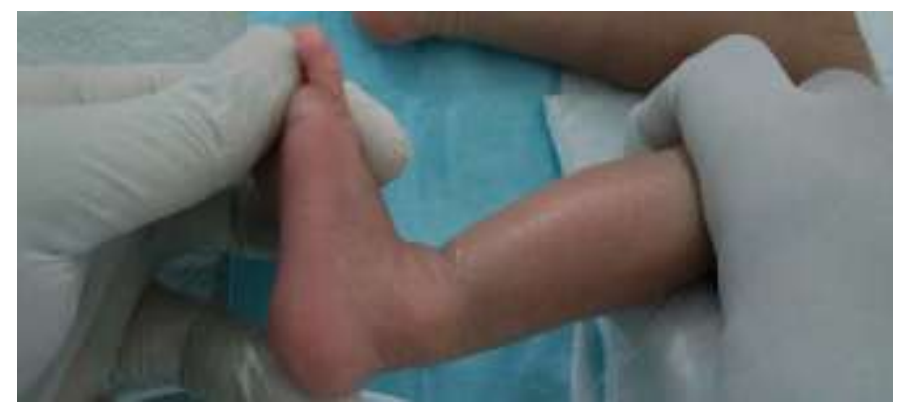

Pre and per-operative picture

Aseptic dressing was done around the tenotomy site. The patient is the given to mother for care of child. Dorsiflexion was then checked and sterile dressing was done. Above knee cast was then applied keeping the ankle on dorsiflexion position. After application of cast, capillary fill of toes and cast was continued for 3 weeks and patient was explained all cast complication and recalled in opd after 3 weeks.

After 3 weeks to prevent relapse of deformity, Dennis-Brown bar with shoes was applied for full time i.e whole day and night, for about 3 months for 23 hours every day and later 2-4 hours a day and 12 hours at night(i.e about 15-16 hour per 24 hour period) till 2 years of age.

\section{Results:-}

Between November 2015 to December 2017 , 30 patients( with idiopathic club foot) were included in the study, out of which 18 male( $60 \%), 12$ female(40\%) were managed. A success of $27(90 \%)$ patients was seen were managed successfully . Due to irregular follow up, improper application of D-B splint, failure with $3(10 \%)$ patients was observed . No complication like formation of blister, excessive bleeding or any neurovascular compromise seen. There was no incidence of local infection in any case .

\section{Discussion:-}

Tenotomy is the major step during management of CTEV after ponseti serial casting. Conventional blade tenotomy achieves good correction, however complications like damage to neurovascular structures leading to bleeding or pseudo aneurysms are reported.$^{7,8}$ This technique is already described in literature ${ }^{4,5}$ and through our study we are providing a detail technical steps for easy learning and hence promote use of this easy and safe procedure.

Ponseti serial casting explains all correction of deformities except equinus correction. Ponseti used an ophthalmic scalpel blade for a percutaneous tenotomy. The long and sharp end of this blade has the potential risk of damaging the structures around the tendon especially, those lateral to it. Obviously, thicker the instrument used to perform tenotomy, more was the risk of damaging nearby structures. Another concern with the percutaneous tenotomy is the risk of incomplete division of the tendon leading to poor correction of equinus deformity and hence early recurrence. Maranho DAC et al., suggested ultrasound guided tenotomy with a wide bore needle to ensure the completeness of this procedure ${ }^{9}$.

\section{Conclusion:-}

In our study we are explaining about minimal invasive percutaneous tenotomy of tendo-achilles after serial ponseti casting using wide bore needle with low complication rates, easy to perform and with excellent results in idiopathic club feet. With use of wide bore needle, there is minimal risk of neurovascular complication and incomplete tenotomy. 


\section{References:-}

1. Wynne-Davies R. Family studies and the cause of congenital club foot, talipes equinovarus, talipes calcaneovalgus and metatarsus varus. J Bone Joint Surg Br. 1964;46:445-463.

2. Ponseti IV. Treatment of congenital club foot. J Bone Joint Surg Am 1992; 74:448-54

3. Bor N, Coplan JA, Herzenberg JE. Ponseti Treatment for idiopathic clubfoot: minimum 5-year follow-up. Clin Orthop Relat Res 2009; 467:1263-70

4. Minkowitz B, Finkelstein BI, Bleicher M. Percutaneous tendo- Achilles lengthening with a large- gauge needle: a modification of the Ponseti technique for correction of idiopathic clubfoot. J Foot Ankle Surg. 2004 Jul-Aug; 43(4): 263-5.

5. Maranha, Daniel Augusto Carvalho, Nogueira-BARBOS Marcello Henrique, Simon, and VOLPON Novelino Marcelo José Batista. Use of large-bore needle in section percutaneous Achilles tendon in congenital clubfoot. ortop Act. Bras. [Online]. 2010, vol.18, n.5 [cited 01/30/2012], pp. 271- 276.

6. Hussain N, Khan T, Ahmed A. Complete subcutaneous tenotomy of tendo-achilles in clubfoot patients - a four year follow up. J Surgery. 2004; 2(1): 17-9.

7. Dobbs MB, Gordon JE, Walton T, Schoenecker PL. Bleeding Complications Following tendoachilles percutaneous tenotomy in the Treatment of clubfoot deformity. J Pediatr Orthop. 2004, 24:353-7.

8. RD Burghardt, JE Herzenberg, A. Ranade Pseudoaneurysm after Ponseti percutaneous Achilles tenotomy: a case report. J Pediatr Orthop. 2008, 28:366-9.

9. Maranho DAC, Nogueira-Barbosa MH, Simão MN, Volpon JB. Use of a large gauge needle for percutaneous sectioning of the Achilles tendon in congenital clubfoot. Acta Ortop Bras. 2010;18(5):271-6. 